\title{
FLEXIBILITY-BASED LINEAR DYNAMIC ANALYSIS OF COMPLEX STRUCTURES WITH CURVED-3D MEMBERS
}

\author{
C. MOLINS ${ }^{1, *, \dagger}$, P. ROCA ${ }^{1, \ddagger}$ AND A. H. BARBAT ${ }^{2, \ddagger}$ \\ ${ }^{1}$ Department of Construction Engineering, Universitat Politècnica de Catalunya, 08034 Barcelona, Spain \\ ${ }^{2}$ Department of Structural Mechanics, Universitat Politècnica de Catalunya, 08034 Barcelona, Spain
}

\section{SUMMARY}

A flexibility-based formulation of a new mass matrix for the dynamic analysis of spatial frames consisting of curved elements with variable cross-sections is presented. The main characteristic of such formulations is the exact equilibrium of forces at any interior point, with no additional hypotheses about the distribution of displacements, strains or stresses. Accordingly, the derived element mass matrix takes into account the exact stiffness and mass distribution throughout each element.

In validation tests, results obtained with this method are compared with those obtained by other numerical or analytical formulations, showing the accuracy of the proposed method. The comparison of experimental results for a multispan arch bridge subjected to a dynamic load with those achieved by means of the proposed method are finally included to illustrate its efficiency in the treatment of complex structures. (C) 1998 John Wiley \& Sons, Ltd.

KEY WORDS: dynamic analysis; 3D frames; flexibility formulation; curved members; variable cross-section; consistent mass matrix

\section{INTRODUCTION}

Curved members with uniform or variable cross-sections (such as arches) were commonly used in ancient buildings due to their optimum appropriateness to non-cohesive construction materials. Moreover, their structural and architectural qualities make them appropriate for use in some modern plain or reinforced concrete structures.

The most commonly used procedures for the static and dynamic analysis of structural systems with curved members are based on either the decomposition of members into polygons of straight elements with uniform thickness, or the displacement formulations of the finite element method with isoparametric curved elements. While the first possibility is just a rough and expensive approach, the second is not free of certain inaccuracies, since it is based on the use of an assumed interpolation of the displacements of the structure. It is known that, because of that interpolation - which acts as an extra condition beyond equilibrium, compatibility and stressstrain relationships - the internal forces are calculated in such a way that they do not satisfy equilibrium in the element in a strict sense.

However, as shown by Baron ${ }^{1}$ curved linear members can also be treated by means of analytical generalizations of the conventional matrix methods based directly on equilibrium. Because no additional hypotheses

\footnotetext{
* Correspondence to: C. Molins, Technical University of Catalonia, Modul C1, Gran Capitan s/n, 08034 Barcelona, Spain. E-mail: dmolins@etseccpb.upc.es

$\dagger$ Assistant Professor

$\ddagger$ Associate Professor

Contract/grant sponsor: Spanish Government; Contract/grant number: SEC93-1160

Contract/grant sponsor: Servei de Patrimoni Local, Diputació de Barcelona
}

CCC 0098-8847/98/070731-17\$17.50

Received 11 December 1996

(C) 1998 John Wiley \& Sons, Ltd. 
are needed in this case - to interpolate the fields of stresses or displacements - only the three conditions on equilibrium, compatibility and stress-strain relationships are superimposed, thus preserving their strict satisfaction.

The practical use of these matrix formulations was limited in the past by the large number of operations that they require. Nowadays, the significant development of digital computers makes this point less critical, while accuracy and versatility gain renewed interest. During recent years, some works on nonlinear analysis of either concrete or steel structures, such as those presented by Mahasuverachai and Powell, ${ }^{2}$ Carol and Murcia, ${ }^{3}$ Marí, ${ }^{4}$ Blandford and Glass ${ }^{5}$ and Zeris and Mahin, ${ }^{6}$ have maintained interest in flexibility-based formulations. More recently, Spacone et al. ${ }^{7,8}$ have used formulations of this kind for non-linear analysis of R/C frames

Besides the exact satisfaction of equilibrium, the use of generalized matrix formulations offers additional possibilities when extended to dynamic analysis. Element mass matrices are usually calculated either in a simplified way, as in the case of lumped mass matrices, or in a consistent way with an assumed hypothesis on the displacement field. The latter is the case of the consistent mass matrices that are used in the finite element method. Generally, the use of consistent mass matrices leads to more exact results than the lumped ones. ${ }^{9}$ Most of the presented formulations of consistent mass matrices are based on cubic interpolations of the displacements along the element; this is the case of the procedures used by Wekezer, ${ }^{10,11}$ Eisenberger and Reich ${ }^{12}$ and Blandford and Glass. ${ }^{5}$ The last authors used a FEM-based mass matrix in combination with

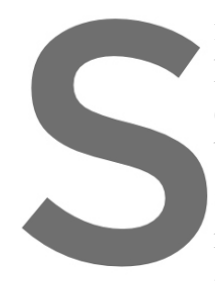
flexibility-based formulation

hybrid-stress interpolation: expression of a mass matrix by direct integration of 1 significant effort devoted refer to linear members authors.

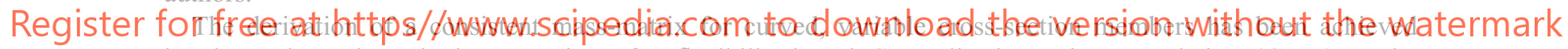
by the authors through the extension of a flexibility-based Generalized Matrix Formulation (GMF) to the dynamic analysis of this type of structure. The most relevant feature of the resulting formulation is that the element mass matrix objectively and systematically takes into account the actual distribution of mass and stiffness within the element, with no hypothesis over the displacements field.

This paper presents the basic GMF environment adopted and the consequent derivation of modal vibration analysis technique, including the above-mentioned consistent mass-matrix for curved and cross-section variable members. After the presentation of two validation tests, the application of the proposed method to a multispan arch bridge and the comparison between analytical and experimental results are described.

\section{STIFFNESS MATRIX}

\subsection{Equation of equilibrium of the element}

The basic formulation for linear elastic analysis is based on a previous proposal by Marí. ${ }^{4}$ The axis of an element can be represented in global co-ordinates by the equation $\Gamma(s)=[X(s), Y(s), Z(s)]$, where $s$ is the arch parameter associated to the reference curve (Figure 1). The local co-ordinate system $\{x, y, z\}$ is defined at each section so that $x$-axis is tangent to the axis of the element and $y$-and $z$-axis are perpendicular to each other and to $x$, and are contained in the plane of the cross-section (Figure 2). The axis of the element may be any arbitrary curve perpendicular to the undeformed cross-sections.

Figure 3 shows an element of infinitesimal length $\mathrm{d} s$ limited by two cross-sections $A$ and $A^{\prime} . O$ and $O^{\prime}$ are the intersection points of the axis with these sections. It is assumed that distributed loads, force $\mathbf{p}$ and moment $\mathbf{m}$, are applied on this element. At both ends, forces and moments $-\mathbf{R}$ and $-\mathbf{M}$ act on point $O$ and $\mathbf{R}+\mathrm{d} \mathbf{R}$ 


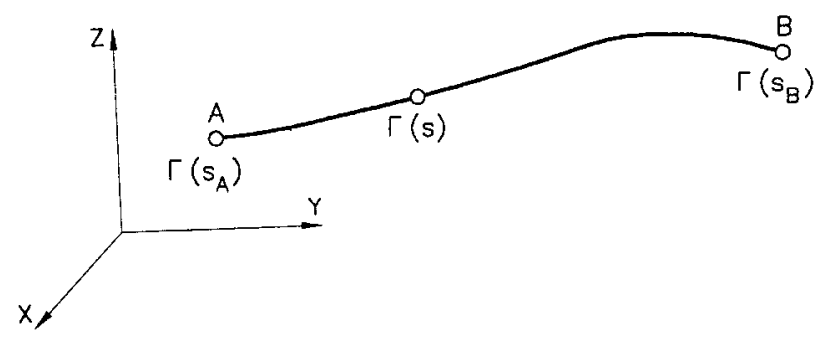

Figure 1. Axis of an element and its curvilinear co-ordinates in the global reference system XYZ

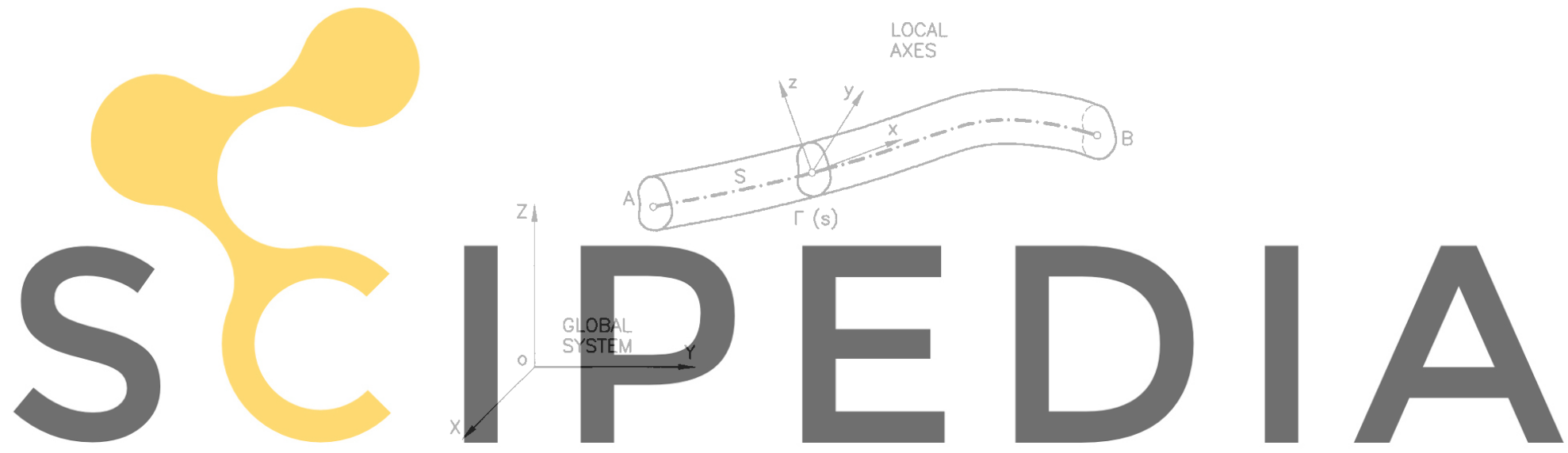

Figure 2. Definition of the local co-ordinates system

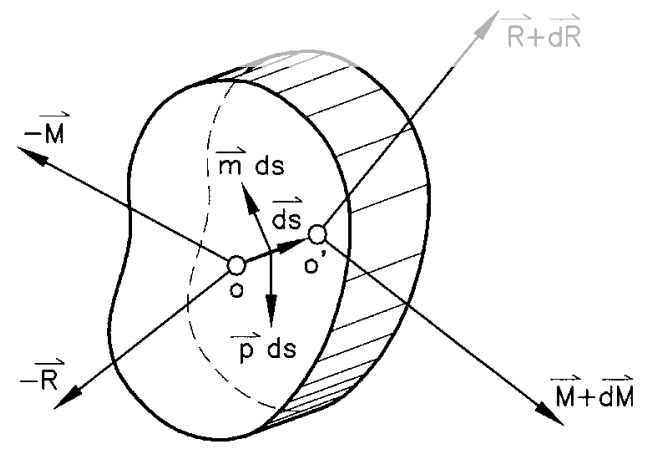

Figure 3. Forces on a cross-section of differential thickness

and $\mathbf{M}+\mathrm{d} \mathbf{M}$ on point $O^{\prime}$, in equilibrium with the applied loads. The resulting equilibrium condition is

$$
\begin{gathered}
\mathrm{d} \mathbf{R}+\mathbf{p d} s=\mathbf{0} \\
-\mathbf{R} \times \mathrm{d} s+\mathrm{d} \mathbf{M}+\mathbf{m} \mathrm{d} s=\mathbf{0}
\end{gathered}
$$

For the present formulation, a cantilever clamped at end $A$ is adopted as basic isostatic configuration, where the independent forces in node $B$ are $\mathbf{P}_{B}=\left[\mathbf{R}_{B}, \mathbf{M}_{B}\right]^{\mathrm{T}}=\left[R_{X B}, R_{Y B}, R_{Z B}, M_{X B}, M_{Y B}, M_{Z B}\right]^{\mathrm{T}}$. This selection is justified by the greater conceptual clarity produced in the subsequent development, which allows a direct 
association of the particular solution with the clamping forces caused by the external loads distributed on the element. According to that, the following matrix equation is obtained integrating equation (1):

$$
\left[\begin{array}{l}
R_{X} \\
R_{Y} \\
R_{Z} \\
M_{X} \\
M_{Y} \\
M_{Z}
\end{array}\right]=\left[\begin{array}{cccccc}
1 & 0 & 0 & 0 & 0 & 0 \\
0 & 1 & 0 & 0 & 0 & 0 \\
0 & 0 & 1 & 0 & 0 & 0 \\
0 & \left(Z-Z_{B}\right) & -\left(Y-Y_{B}\right) & 1 & 0 & 0 \\
-\left(Z-Z_{B}\right) & 0 & \left(X-X_{B}\right) & 0 & 1 & 0 \\
\left(Y-Y_{B}\right) & -\left(X-X_{B}\right) & 0 & 0 & 0 & 1
\end{array}\right]\left[\begin{array}{c}
R_{X B} \\
R_{Y B} \\
R_{Z B} \\
M_{X B} \\
M_{Y B} \\
M_{Z B}
\end{array}\right]+\left[\begin{array}{c}
R_{X}^{*} \\
R_{Y}^{*} \\
R_{Z}^{*} \\
M_{X}^{*} \\
M_{Y}^{*} \\
M_{Z}^{*}
\end{array}\right]
$$

Equation (2) can be written in the following compact form:

$$
\sigma_{X Y}(s)=\mathbf{N}\left(s, s_{B}\right) \mathbf{P}_{B}+\boldsymbol{\sigma}_{X Y}^{*}(s)
$$

where $\mathbf{N}\left(s, s_{B}\right)$ is an interpolation matrix which describes the exact equilibrium of forces between sections $B$ and $s, \sigma_{X Y}(s)$ is the vector of internal forces in the global co-ordinate system expressed as a function of the curvilinear coordinate $s$. The particular solution $\sigma_{X Y}^{*}(s)$ describes the vector of forces produced by the distributed loads on the basic isostatic configuration, that is determined by

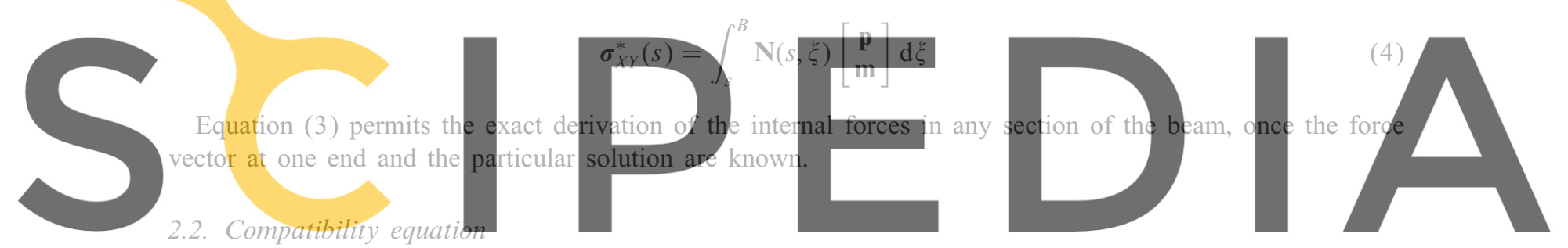

The Navier-Bresse kinematic equations for a spatial curved beam, ${ }^{15}$ can be expressed as

Register for free at https//www.scipedia.com to download the version without the watermark

$$
\begin{gathered}
\omega(s)=\omega\left(s_{0}\right)+\int_{s_{0}} \Omega(\xi) \mathrm{d} \xi \\
\lambda(s)=\lambda\left(s_{0}\right)+\boldsymbol{\omega}\left(s_{0}\right) \times\left(\boldsymbol{\Gamma}(s)-\boldsymbol{\Gamma}\left(s_{0}\right)\right)+\int_{s_{0}}^{s}(\boldsymbol{\Lambda}(\xi)+\boldsymbol{\Omega}(\xi) \times(\boldsymbol{\Gamma}(s)-\boldsymbol{\Gamma}(\xi))) \mathrm{d} \xi
\end{gathered}
$$

where $\lambda(s)=\left[u_{X}, u_{Y}, u_{Z}\right]$ and $\omega(s)=\left[\theta_{X}, \theta_{Y}, \theta_{Z}\right]$ are the vectors of translations and rotations of the axis at the curvilinear coordinate point $s ; \boldsymbol{\Lambda}(\xi)=\left[\varepsilon_{X}, \varepsilon_{Y}, \varepsilon_{Z}\right]$ and $\boldsymbol{\Omega}(\xi)=\left[\phi_{X}, \phi_{Y}, \phi_{Z}\right]$ are the vectors of strains and curvatures of the section at the curvilinear co-ordinate point $\xi$; and $\boldsymbol{\Gamma}=[X, Y, Z]$ is the reference vector of points belonging to the element axis.

Applying the previous conditions (5) and (6) to ends $A$ and $B$ of the member, the following equation is obtained

$$
\boldsymbol{\delta}_{B}=\mathbf{N}^{\mathrm{T}}\left(s_{A}, s_{B}\right) \boldsymbol{\delta}_{A}+\int_{A}^{B} \mathbf{N}^{\mathrm{T}}\left(s, s_{B}\right) \boldsymbol{\epsilon}_{X Y}(s) \mathrm{d} s
$$

where $\boldsymbol{\delta}_{A}=\left[u_{X A}, u_{Y A}, u_{Z A}, \theta_{X A}, \theta_{Y A}, \theta_{Z A}\right]^{\mathrm{T}}$ and $\boldsymbol{\delta}_{B}=\left[u_{X B}, u_{Y B}, u_{Z B}, \theta_{X B}, \theta_{Y B}, \theta_{Z B}\right]^{\mathrm{T}}$ are the displacement vectors at ends $A$ and $B . \epsilon_{X Y}(s)=\left[\varepsilon_{X}, \varepsilon_{Y}, \varepsilon_{Z}, \phi_{X}, \phi_{Y}, \phi_{Z}\right]^{\mathrm{T}}$ is the generalized strain vector in global co-ordinates of the section with curvilinear co-ordinate $s$.

The second term in equation (7) gives the movement of end $B$ caused by the deformation of the element

$$
\mathbf{d}=\boldsymbol{\delta}_{B}-\mathbf{N}^{\mathrm{T}}\left(s_{A}, s_{B}\right) \boldsymbol{\delta}_{A}=\int_{A}^{B} \mathbf{N}^{\mathrm{T}}\left(s, s_{B}\right) \boldsymbol{\epsilon}_{X Y}(s) \mathrm{d} s
$$




\subsection{Constitutive model at the section level}

As a first approach, the following hypotheses regarding the mechanical behaviour of the members are introduced: (1) linear elastic response is assumed; (2) Bernoulli's hypothesis is maintained, so that crosssections remain plane after deformation of the element, although, due to shear deformation, they do not necessarily remain perpendicular to the axis; (3) tangential forces (shear and torsion) and normal forces (axial and bending) are assumed to be completely uncoupled; thus, their possible interaction at the sectional level is not taken into account; and, (4) Saint Venant torsion is assumed, where free warping of the cross-sections is allowed, and the angle of twist is directly proportional to the torsional moment at each section.

Based on the previous hypotheses, it is possible to outline a constitutive relationship between sectional forces and sectional strains. In local co-ordinates, the more general form of this equation is

$$
\sigma_{s}=\mathbf{K}_{s}\left(\epsilon_{s}-\epsilon_{s}^{o}\right)+\sigma_{s}^{o}
$$

where $\sigma_{s}=\left[N, V_{y}, V_{z}, M_{x}, M_{y}, M_{z}\right]^{\mathrm{T}}$ is the vector of sectional forces, $\epsilon_{s}=\left[\varepsilon_{x}, \varepsilon_{y}, \varepsilon_{z}, \phi_{x}, \phi_{y}, \phi_{z}\right]^{\mathrm{T}}$, is the vector of sectional strains ( $\varepsilon_{x}$ being the axial strain, $\varepsilon_{y}$ and $\varepsilon_{z}$ the tangential strains, $\phi_{x}$ the twist curvature and $\phi_{y}, \phi_{z}$ the flexure curvatures), $\mathbf{K}_{s}$ is the sectional stiffness matrix, which depends on the shape of the section and on the elastic characteristics of the materials, $\sigma_{s}^{0}$ is the vector of forces due to initial stresses and $\epsilon_{s}^{0}$ is the

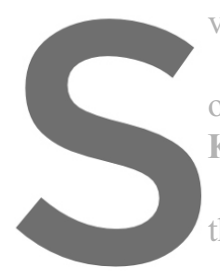
vector of initial strains of

The matrix $\mathbf{K}_{s}$ is obtained of kinematic compatibility $\mathbf{K}_{s}$ may be found in Moli

The lack of coupling be the normal and shear constitit
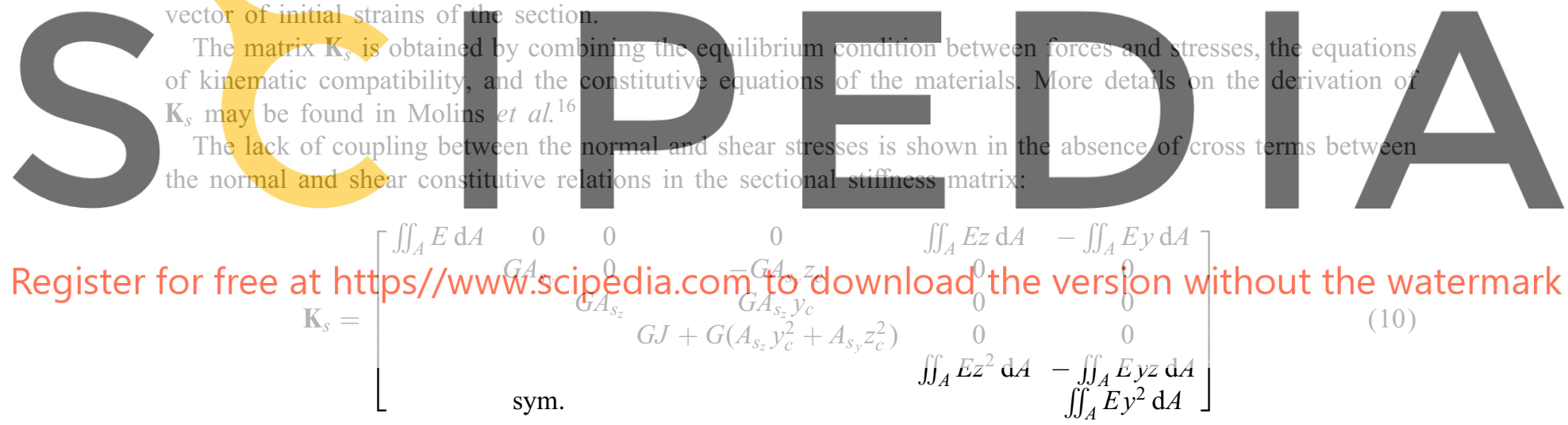

where $E$ is Young's modulus of the material at point $(y, z)$ of the cross-section, $G$ is the shear modulus of the material, $J$ is the torsional inertia of the section, $\left(y_{c}, z_{c}\right)$ are the local co-ordinates of the shear center, and $A_{s_{y}}, A_{s_{z}}$ are the reduced areas of the section for shear forces in the local directions $y$ and $z$.

\subsection{Equation of the element}

Rewriting equation (9) in global co-ordinates with a rotation matrix $\mathbf{C}$ (where $\boldsymbol{\sigma}_{s}=\mathbf{C} \boldsymbol{\sigma}_{X Y}, \boldsymbol{\epsilon}_{s}=\mathbf{C} \boldsymbol{\epsilon}_{X Y}$, and $\left.\mathbf{C}^{T}=\mathbf{C}^{-1}\right)$, the following expression is obtained:

$$
\mathbf{C} \boldsymbol{\sigma}_{X Y}=\mathbf{K}_{s}\left(\mathbf{C} \epsilon_{X Y}+\boldsymbol{\epsilon}_{S}^{o}\right)+\mathbf{C} \boldsymbol{\sigma}_{X Y}^{o}
$$

Solving equation (11), the following equation of the strain vector in global co-ordinates $\epsilon_{X Y}$ is obtained

$$
\boldsymbol{\epsilon}_{X Y}=\mathbf{C}^{\mathrm{T}} \mathbf{K}_{s}^{-1} \mathbf{C}\left(\boldsymbol{\sigma}_{X Y}-\boldsymbol{\sigma}_{X Y}^{o}\right)-\mathbf{C}^{\mathrm{T}} \boldsymbol{\epsilon}_{s}^{o}
$$

The substitution of the strain vector (12) in equation (8) gives

$$
\mathbf{d}=\boldsymbol{\delta}_{B}-\mathbf{N}^{\mathrm{T}}\left(s_{A}, s_{B}\right) \boldsymbol{\delta}_{A}=\int_{A}^{B} \mathbf{N}^{\mathrm{T}}\left(s, s_{B}\right)\left(\mathbf{C}^{\mathrm{T}} \mathbf{K}_{s}{ }^{-1} \mathbf{C}\left(\boldsymbol{\sigma}_{X Y}-\boldsymbol{\sigma}_{X Y}^{o}\right)-\mathbf{C}^{\mathrm{T}} \boldsymbol{\epsilon}_{s}^{o}\right) \mathrm{d} s
$$


The equilibrium equation (3) allows the internal sectional forces at any point to be related to the forces $\mathbf{P}_{A}$ and $\mathbf{P}_{B}$ at the ends of the element. Substituting equation (3) in equation (13) yields

$$
\begin{aligned}
\mathbf{d}= & \int_{A}^{B}\left(\mathbf{N}^{\mathrm{T}}\left(s, s_{B}\right) \mathbf{C}^{\mathrm{T}} \mathbf{K}_{s}^{-1} \mathbf{C} \mathbf{N}\left(s, s_{B}\right) \mathbf{P}_{B}+\mathbf{N}^{\mathrm{T}}\left(s, s_{B}\right) \mathbf{C}^{\mathrm{T}} \mathbf{K}_{s}{ }^{-1} \mathbf{C} \boldsymbol{\sigma}_{X Y}^{*}\right. \\
& \left.-\mathbf{N}^{\mathrm{T}}\left(s, s_{B}\right) \mathbf{C}^{\mathrm{T}} \mathbf{K}_{s}{ }^{-1} \mathbf{C} \boldsymbol{\sigma}_{X Y}^{o}-\mathbf{N}^{\mathrm{T}}\left(s, s_{B}\right) \mathbf{C}^{\mathrm{T}} \boldsymbol{\epsilon}_{s}^{o}\right) \mathrm{d} s
\end{aligned}
$$

This equation can be written in shorter form as

$$
\mathbf{d}=\mathbf{F} \mathbf{P}_{B}+\mathbf{d}^{*}+\mathbf{d}^{o}
$$

where $\mathbb{F}=\int_{A}^{B} \mathbf{N}^{\mathrm{T}} \mathbf{C}^{\mathrm{T}} \mathbf{K}_{s}^{-1} \mathrm{CN} d s$ is the flexibility matrix of a member. $\mathbf{d}^{*}=\int_{A}^{B} \mathbf{N}^{\mathrm{T}} \mathbf{C}^{\mathrm{T}} \mathbf{K}_{s}^{-1} \mathbf{C} \sigma_{X Y}^{*} \mathrm{~d} s$ is the vector of displacements in $B$ produced by the deformation of the element in its basic isostatic configuration under the effect of distributed loads, and $\mathbf{d}^{o}=\int_{A}^{B} \mathbf{N}^{\mathrm{T}} \mathbf{C}^{\mathrm{T}}\left(\mathbf{K}_{s}^{-1} \mathbf{C} \boldsymbol{\sigma}_{X Y}^{o}-\epsilon_{s}^{o}\right) \mathrm{d} s$ is the vector of displacements in $B$ due to the initial strains and stresses.

The stiffness matrix of an element is obtained by formulating the explicit relationship between forces and nodal displacements. For extremity $B$, this relationship is immediately obtained from equations (8) and (15)

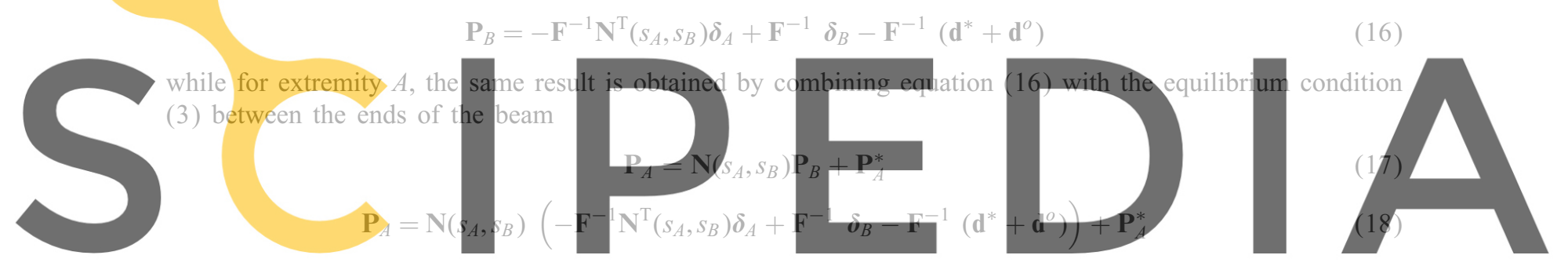

Both relationships (16) and (18) can be combined in the matrix expression

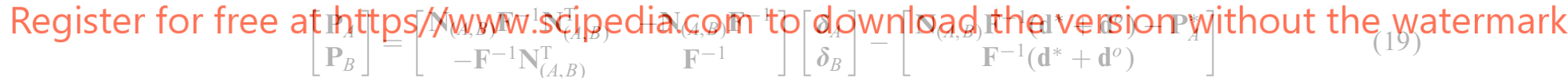

where $\mathbf{N}_{(A, B)}=\mathbf{N}\left(s_{A}, s_{B}\right)$. Equation (19) can be written in a more compact form as

$$
\mathbf{P}=\mathbf{K} \boldsymbol{\delta}+\mathbf{P}^{* o}
$$

where $\mathbf{P}$ is the vector of end forces, $\mathbf{K}$ is the stiffness matrix of the element, $\boldsymbol{\delta}$ is the vector of end displacements and $\mathbf{P}^{* 0}$ is the vector of the reactions corresponding to perfect clamping at the ends of the element due to initial strains and stresses.

\section{MASS MATRIX}

The equation of motion that governs the dynamic response of the structure can be formulated as

$$
\mathbf{M} \ddot{\boldsymbol{\delta}}(t)+\mathbf{D} \dot{\boldsymbol{\delta}}(t)+\mathbf{K} \boldsymbol{\delta}(t)=\mathbf{F}(t)
$$

where $\mathbf{M}$ is the mass matrix, $\mathbf{D}$ is the damping matrix, $\mathbf{K}$ is the stiffness matrix, $\boldsymbol{\delta}(t)$ is the vector of displacements and $\mathbf{F}(t)$ is the dynamic force.

The derivation of a consistent mass matrix using the present formulation is achieved through the definition of a sectional mass matrix and a description of a displacement field in the element, as may be seen in Sections 3.1 and 3.2. A relevant feature of the resulting formulation is that the element mass matrix incorporates information related to the geometry, stiffness distribution and mass density within the element.

D'Alembert's principle is applied to obtain the dynamic equilibrium equation of the element. This is achieved by identifying the inertia forces acting on any point at a given instant, and then applying the static equilibrium equations as shown in Section 3.3. 


\subsection{Sectional mass matrix}

In order to obtain the inertial forces that act on a section, it is necessary to assume the additional hypothesis that cross-sections are moved as rigid bodies in their plane. According to this hypothesis, the inertia forces in local co-ordinates $\mathbf{f}_{I}(s)=\left[f_{I_{x}}(s), f_{I_{y}}(s), f_{I_{z}}(s), f_{I_{x x}}(s), f_{I_{y y}}(s), f_{I_{z z}}(s)\right]^{\mathrm{T}}$, which correspond to any cross-section of curvilinear co-ordinate $s$, can be calculated as a function of the accelerations as follows:

$$
\mathbf{f}_{I}(s)=\mathbf{M}_{s}(s) \ddot{\boldsymbol{\delta}}(s)
$$

where

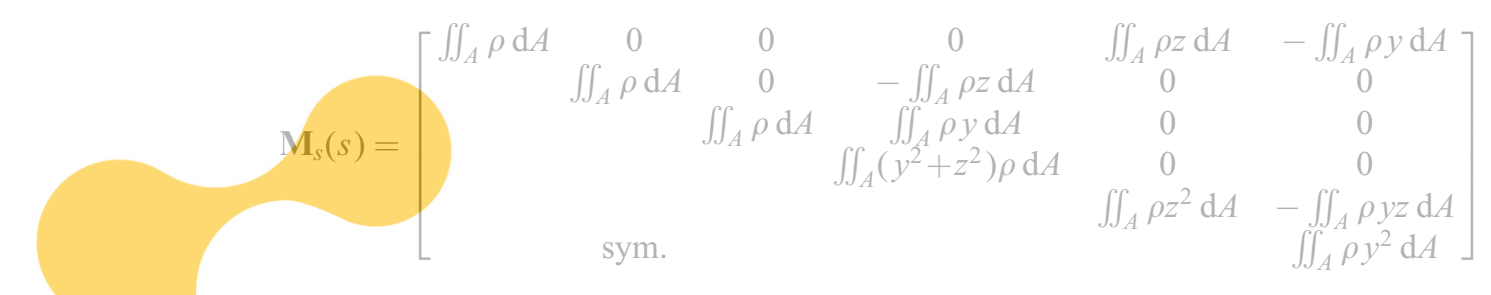

is the sectional mass matrix and the vector $\ddot{\delta}(s)=\left[\ddot{u}_{x}(s), \ddot{u}_{y}(s), \ddot{u}_{z}(s), \ddot{\theta}_{x}(s), \ddot{\theta}_{y}(s), \ddot{\theta}_{z}(s)\right]^{\mathrm{T}}$ describes the acceleration of a point on the

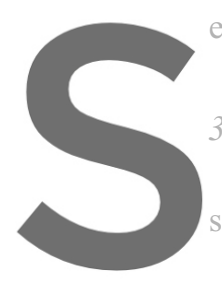

3.2. Expression for displ

The combination of equations ( 3 ) strains $\epsilon_{X Y}(s)$ to the forces $\mathbf{P}_{B}$ at the
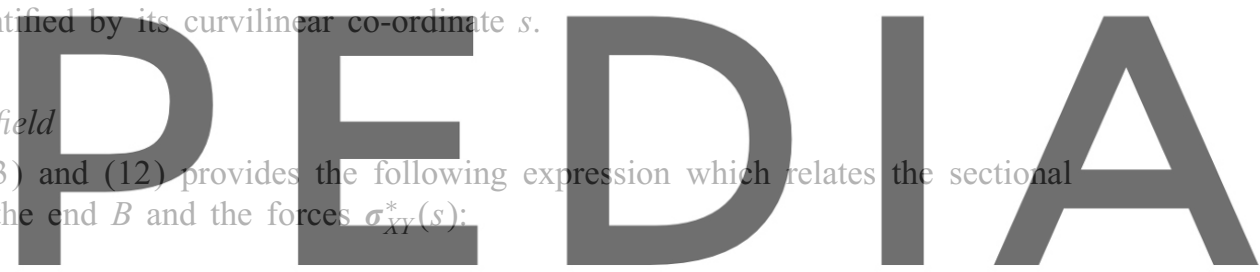

$$
\epsilon_{X Y}(s)=\mathbb{C}^{\mathrm{T}}(s) \mathbb{K}_{s}^{-1}(s) \mathbb{C}(s)\left(\mathrm{N}\left(s, s_{B}\right) \mathbb{P}_{B}+\sigma_{X Y}^{*}(s)\right)
$$

Register for free at https//www.scipedia.com to download the version without the watermark

If it is assumed that the beam does not carry distributed loads $\left(\sigma_{X Y}^{*}=\mathbf{0}\right.$ and $\left.\mathbf{d}^{*}=\mathbf{0}\right)$, equations (16) and (24)

may be combined into the following expression:

$$
\boldsymbol{\epsilon}_{X Y}(\xi)=\mathbf{C}^{\mathrm{T}}(\xi) \mathbf{K}_{s}^{-1}(\xi) \mathbf{C}(\xi) \mathbf{N}\left(\xi, s_{B}\right)\left(\mathbf{F}^{-1} \boldsymbol{\delta}_{B}-\mathbf{F}^{-1} \mathbf{N}_{(A, B)}^{\mathrm{T}} \boldsymbol{\delta}_{A}\right)
$$

The substitution of equation (25) in equation (7) yields

$$
\boldsymbol{\delta}(s)=\mathbf{G}(s)\left[\begin{array}{l}
\boldsymbol{\delta}_{A} \\
\boldsymbol{\delta}_{B}
\end{array}\right]
$$

where

$$
\mathbf{G}(s)=\left[\mathbf{N}^{\mathrm{T}}\left(s_{A}, s\right)-\mathbf{F}_{s}(s) \mathbf{F}^{-1} \mathbf{N}_{(A, B)}^{\mathrm{T}} \quad \mathbf{F}_{s}(s) \mathbf{F}^{-1}\right]
$$

is the matrix which relates the internal displacements of the element to the node displacements and

$$
\mathbf{F}_{s}(s)=\int_{s_{A}}^{s} \mathbf{N}^{\mathrm{T}}(\xi, s) \mathbf{C}^{\mathrm{T}}(\xi) \mathbf{K}_{s}^{-1}(\xi) \mathbf{C}(\xi) \mathbf{N}\left(\xi, s_{B}\right) \mathrm{d} \xi
$$

Expression (26) allows the calculation of displacements of any point in the axis of the element with respect to the nodal displacements. It is exact when the deformation of the element is caused only by the displacement of its ends. Otherwise, the local influence of distributed loads in the deformed shape is neglected, so that equation (26) is to be regarded as an approximation. 


\subsection{Determination of mass matrix}

By applying d'Alembert's principle, it is possible to proceed in the same way as for the static case and obtain the forces caused by loads distributed on the basic isostatic configuration of the element. Hence, as in equation (4),

$$
\boldsymbol{\sigma}_{X Y}^{*}(s)=\int_{s}^{B} \mathbf{N}(s, \xi) \mathbf{f}_{I_{X Y}}(\xi) \mathrm{d} \xi
$$

where $\mathbf{f}_{I_{X Y}}(\xi)$ is the vector of inertia loads in global co-ordinates in the section of curvilinear co-ordinate $\xi$. Relating the inertia forces to the corresponding nodal accelerations, this vector can be written as

$$
\mathbf{f}_{I_{X Y}}(\xi)=\mathbb{C}^{\mathrm{T}} \mathbf{M}_{S} \ddot{\delta}(\xi)=\mathbb{C}^{\mathrm{T}} \mathbf{M}_{S} \mathbf{G}(\xi)\left[\begin{array}{l}
\ddot{\delta}_{A} \\
\ddot{\delta}_{B}
\end{array}\right]
$$

The vector $\mathbf{d}^{*}$ of the displacements in $B$ corresponding only to the deformation of the beam itself, produced by the forces $\sigma_{X Y}^{*}$ of equation (29), can be expressed as

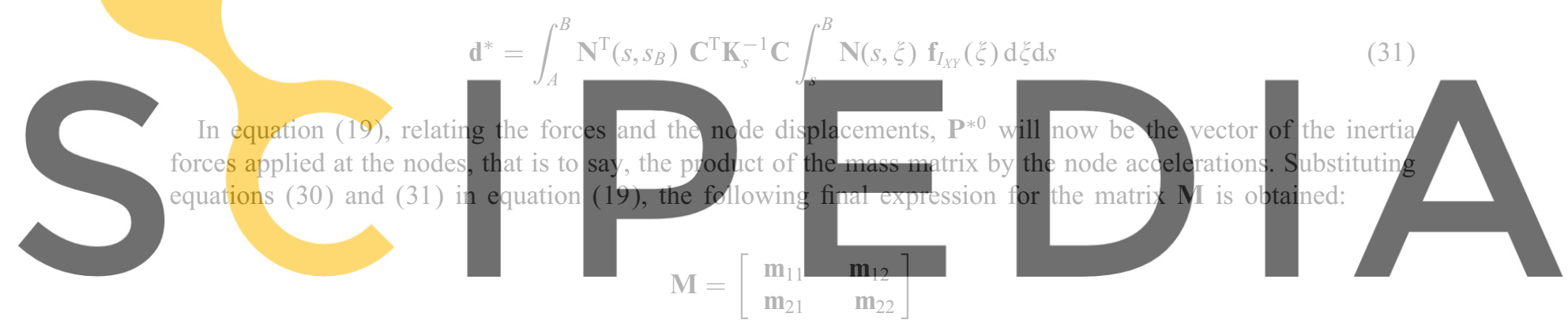

Register for free at https//www.scipedia.com to download the version without the watermark

$$
\begin{gathered}
\mathbf{m}_{22}=\mathbf{F}^{-1} \int_{A}^{B} \mathbf{N}^{\mathrm{T}}\left(s, s_{B}\right) \mathbf{C}^{\mathrm{T}}(s) \mathbf{K}_{s}^{-1}(s) \mathbf{C}(s)\left(\int_{s}^{B} \mathbf{N}(s, \xi) \mathbf{C}^{\mathrm{T}}(\xi) \mathbf{M}_{s}(\xi) \mathbf{C}(\xi) \mathbf{F}_{s}(\xi) \mathbf{F}^{-1} \mathrm{~d} \xi\right) \mathrm{d} s \\
\mathbf{m}_{21}=\mathbf{F}^{-1} \int_{A}^{B} \mathbf{N}^{\mathrm{T}}\left(s, s_{B}\right) \mathbf{C}^{\mathrm{T}}(s) \mathbf{K}_{s}^{-1}(s) \mathbf{C}(s)\left(\int_{s}^{B} \mathbf{N}(s, \xi) \mathbf{C}^{\mathrm{T}}(\xi) \mathbf{M}_{s}(\xi) \mathbf{C}(\xi)\left(\mathbf{N}^{\mathrm{T}}(A, \xi)-\mathbf{F}_{s}(\xi) \mathbf{F}^{-1} \mathbf{N}^{\mathrm{T}}(A, B)\right) \mathrm{d} \xi\right) \mathrm{d} s \\
\mathbf{m}_{12}=m_{21}^{\mathrm{T}}=-\mathbf{N}(A, B) \mathbf{m}_{22}+\int_{A}^{B} \mathbf{N}^{\mathrm{T}}\left(s_{A}, s\right) \mathbf{C}^{\mathrm{T}}(s) \mathbf{M}_{s}(s) \mathbf{C}(s) \mathbf{F}_{s}(s) \mathbf{F}^{-1} \mathrm{~d} s \\
\mathbf{m}_{11}=-\mathbf{N}(A, B) \mathbf{m}_{21}+\int_{A}^{B} \mathbf{N}^{\mathrm{T}}\left(s_{A}, s\right) \mathbf{C}^{\mathrm{T}}(s) \mathbf{M}_{s}(s) \mathbf{C}(s)\left(\mathbf{N}^{\mathrm{T}}\left(s_{A}, s\right)-\mathbf{F}_{s}(s) \mathbf{F}^{-1} \mathbf{N}^{\mathrm{T}}(A, B)\right) \mathrm{d} s
\end{gathered}
$$

It can be shown that if the proposed method is specialized to a straight beam with uniform cross-section and centred reference axis, the resulting symmetric mass matrix coincides with that proposed by Archer. ${ }^{17}$ 
This researcher developed a FEM consistent mass matrix using a cubic interpolation for the displacement field which took into account shear deformation.

Integration along the axis of the element is carried out using a multiple Simpson's rule with a variable number of points. Consideration of 11 integration points is usually sufficient to obtain the stiffness matrix of any element with curved-3D axis and variable cross-section. However, the computation of the mass matrix includes three integration levels and needs more accurate rules together with a set of additional integration points. ${ }^{18}$

\section{VALIDATION TESTS}

\subsection{Validation test 1: tapered cantilever}

The first validation test consists of the modal analysis of a cantilever beam with straight axis and rectangular cross-section of gradually decreasing depth. It has a length $(L)$ of $10.0 \mathrm{~m}$ and a constant width of $1.0 \mathrm{~m}$. The depth varies linearly from a maximum of $1 \mathrm{~m}$ at the clamped end to zero at the free end. The mechanical properties considered for the material are as follows: deformation modulus $(E) 10^{6} \mathrm{kN} / \mathrm{m}^{2}$ and shear modulus (G) $10^{6} \mathrm{kN} / \mathrm{m}^{2}$. This structure is studied under the effect of its mass, considering a density of $10 \mathrm{kN} / \mathrm{m}^{3}$.

The dynamic analysis consisted of the evaluation of the frequencies for the first natural modes of vibration of the cantilever. The frequency $f_{1}$, corresponding to the first mode, was compared with the exact solution

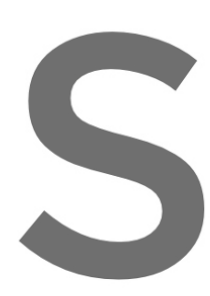
provided by Timoshenko

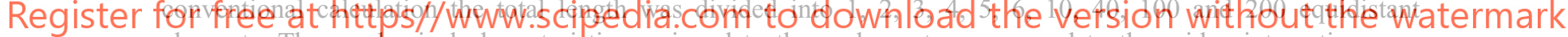

elements. The mechanical characteristics assigned to these elements correspond to the mid-point section.

Table I shows the frequencies obtained for the first five modes of vibration using 8 elements for the proposed method, and 10, 40, 100 and 200 uniform straight elements for the conventional matrix computation. Note that the exact result for the frequency of the first mode without shear deformation is $f_{1}=2.442 \mathrm{~Hz}$ (equation (36)). Figures 4 and 5 show the frequency values for the first and second modes of vibration as a function of the number of elements.

\subsection{Validation test 2: circular helicoidal beam of Young and Scordelis ${ }^{20}$}

The second validation test deals with the modal analysis of a circular helicoid clamped at its two ends, which was previously studied analytically and experimentally by Young and Scordelis ${ }^{20}$ under static loads. The horizontal projection of the helicoid encompasses $180^{\circ}$ and has a constant slope of $30^{\circ}$ (Figure 6). The radius $(R)$ is $0.254 \mathrm{~m}$. The cross-section is rectangular, with a depth of $0.0061976 \mathrm{~m}$ and a width $0.0262382 \mathrm{~m}$.

Table I. Results for the first 5 frequencies in test 1

\begin{tabular}{|c|c|c|c|c|c|c|}
\hline & Elements & $f_{1}$ & $f_{2}$ & $f_{3}$ & $f_{4}$ & $f_{5}$ \\
\hline Proposed & 8 & 2.436 & $6 \cdot 951$ & $13 \cdot 723$ & $22 \cdot 675$ & $34 \cdot 215$ \\
\hline Conventional & 200 & $2 \cdot 436$ & $6 \cdot 950$ & $13 \cdot 658$ & $22 \cdot 504$ & $33 \cdot 398$ \\
\hline Conventional & 100 & $2 \cdot 435$ & $6 \cdot 939$ & $13 \cdot 590$ & $22 \cdot 25$ & $32 \cdot 494$ \\
\hline Conventional & 40 & $2 \cdot 430$ & $6 \cdot 8575$ & $12 \cdot 973$ & 18.928 & 25.675 \\
\hline Conventional & 10 & $2 \cdot 311$ & $4 \cdot 831$ & $8 \cdot 299$ & $15 \cdot 714$ & $27 \cdot 013$ \\
\hline
\end{tabular}




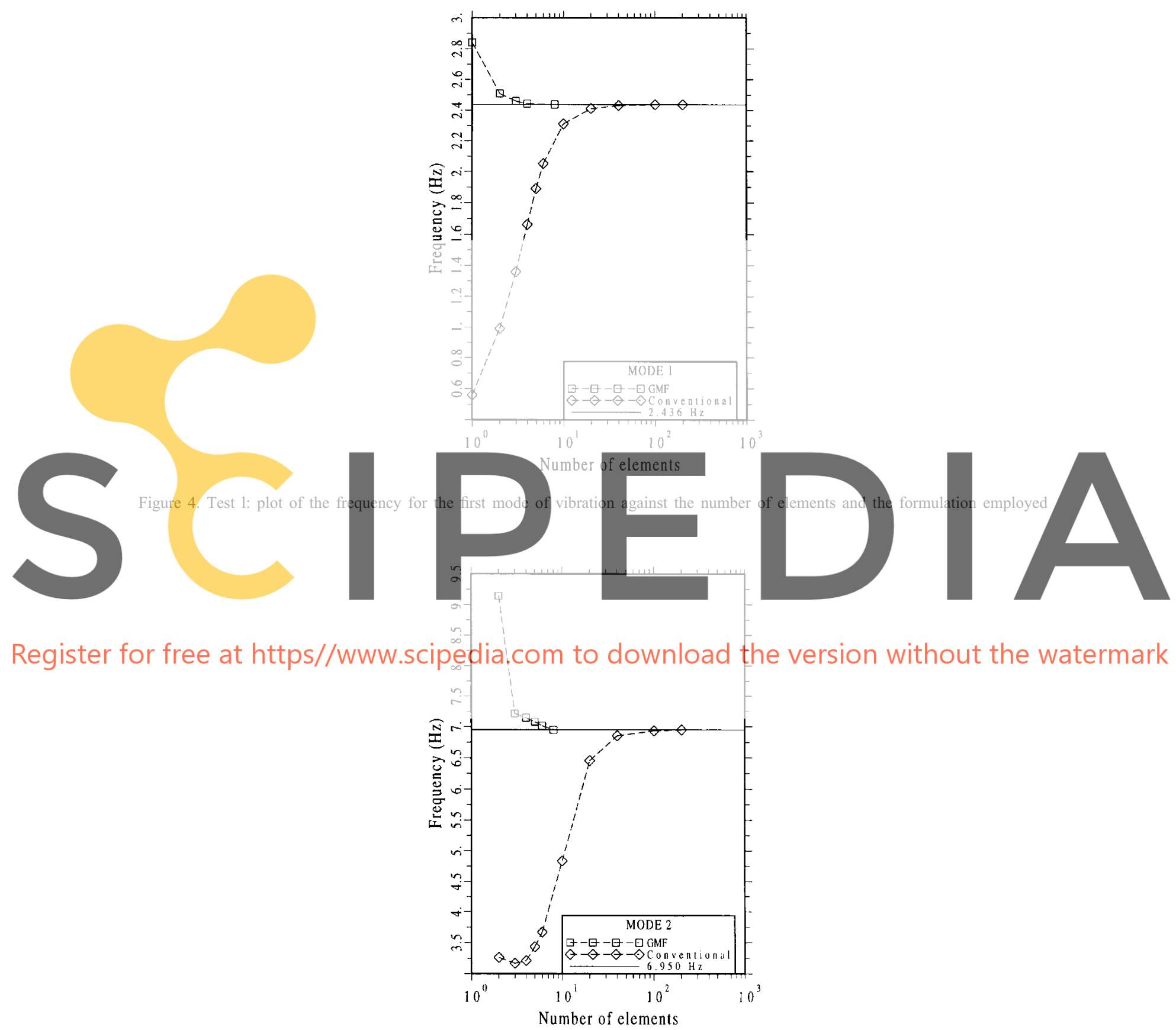

Figure 5. Test 1: plot of the frequency for the second mode of vibration against the number of elements and the formulation employed

The material is characterized by the following mechanical properties: deformation modulus $(E) 3185.5 \mathrm{MPa}$ and shear modulus $(G) 1117 \cdot 0 \mathrm{MPa}$. The density adopted for the material is $10^{6} \mathrm{~kg} / \mathrm{m}^{3}$.

The vibration analysis was performed using both the proposed consistent mass matrix and the lumped mass matrix. The shapes of the first and the third modes of vibration are plotted in Figures 7 and 8. 

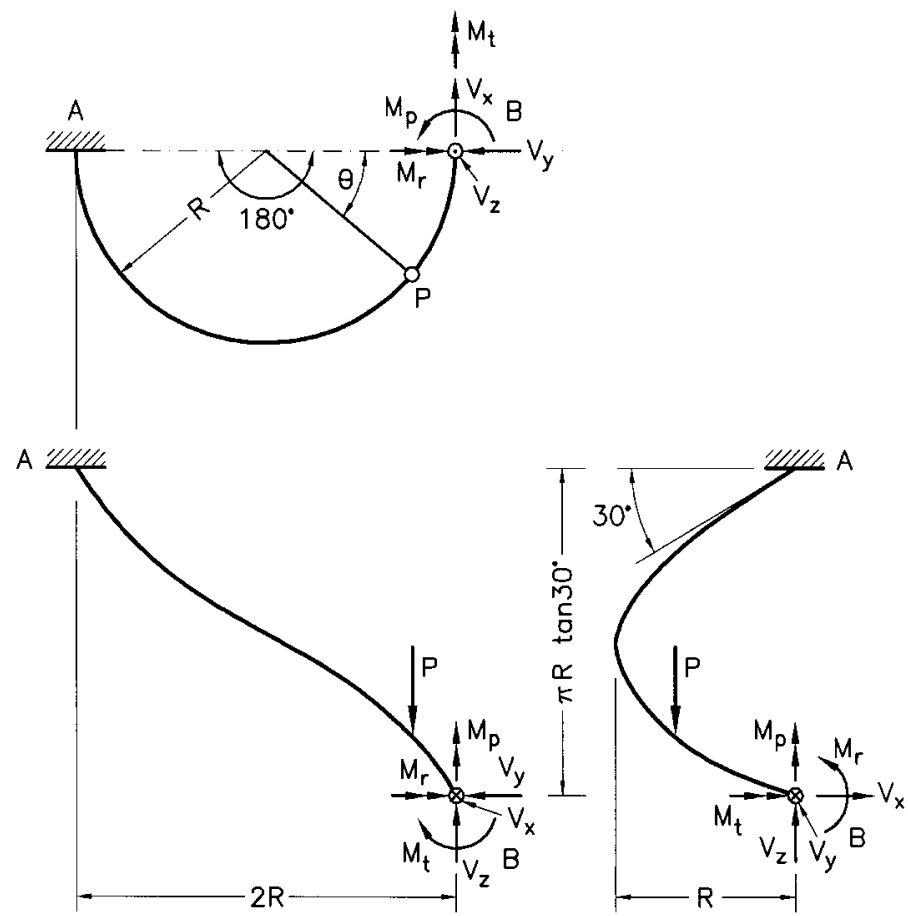

Figure 6. Test 2: Plan and section of the helicoid studied by Young and Scordelis ${ }^{20}$

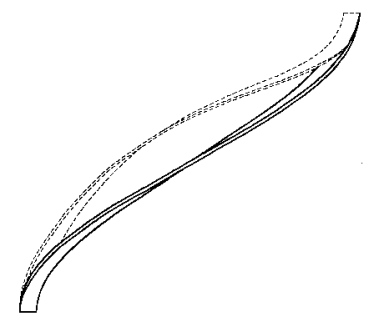

FRONT ELEVATION

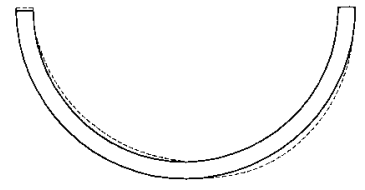

PLAN

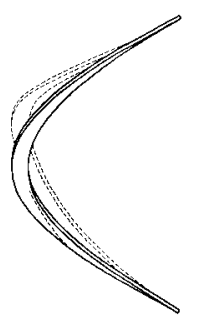

SIDE ELEVATION

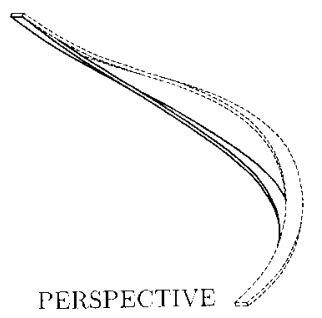

Figure 7. Test 2: Shape of the first mode of vibration (plan, elevation, profile and perspective)

Table II shows the frequencies calculated for the first three modes of vibration using models with 2, 3, 4, and 6 elements, and their relative errors (in brackets). In all cases, the results obtained by using consistent mass matrices are more accurate than those corresponding to lumped mass matrices. This is so even if a model with only two elements is used in combination with the proposed mass matrix. This example points 


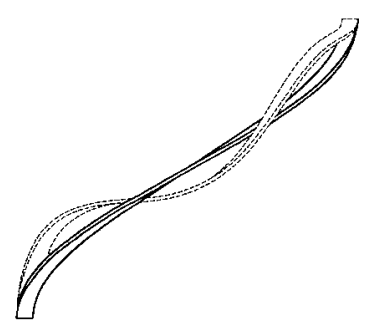

FRONT ELEVATION

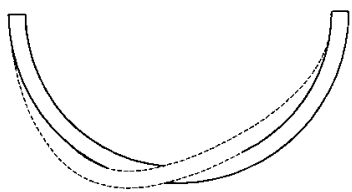

PLAN

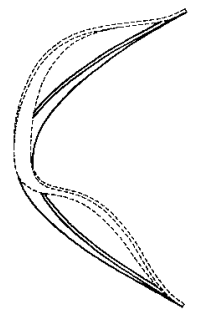

SIDE ELEVATION

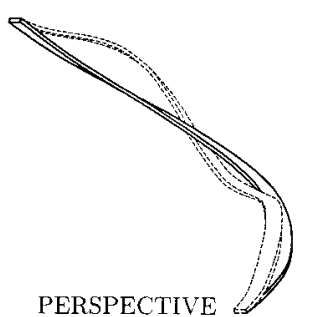

Figure 8. Test 2: Shape of the third mode of vibration (plan, elevation, profile and perspective)

Table II. Frequencies of the three first modes of vibration in test 2

\begin{tabular}{|c|c|c|c|c|c|}
\hline & $\begin{array}{l}\text { Mass } \\
\text { matrix }\end{array}$ & $\begin{array}{c}2 \\
\text { Elements }\end{array}$ & $\begin{array}{c}3 \\
\text { Elements }\end{array}$ & $\begin{array}{c}4 \\
\text { Elements }\end{array}$ & $\begin{array}{c}6 \\
\text { Elements }\end{array}$ \\
\hline$f_{1}$ & Lumped & $0 \cdot 634(-20 \cdot 5 \%)$ & $0.786(-1.5 \%)$ & $0 \cdot 800(+0 \cdot 3 \%)$ & $0.797(-0.1 \%)$ \\
\hline $0.798 \mathrm{~Hz}$ & Consistent & $0 \cdot 810(+1 \cdot 5 \%)$ & $0.799(+0 \cdot 1 \%)$ & $0.797(-0.1 \%)$ & $0.798(+0.0 \%)$ \\
\hline$f_{2}$ & Lumped & $3 \cdot 174(+103 \cdot 0 \%)$ & $1 \cdot 211(-22 \cdot 6 \%)$ & $1 \cdot 544(-1 \cdot 3 \%)$ & $1.556(-0.6 \%)$ \\
\hline $1 \cdot 565 \mathrm{~Hz}$ & Consistent & $1 \cdot 862(+19 \cdot 0 \%)$ & $1 \cdot 568(+0 \cdot 2 \%)$ & $1.578(+0.8 \%)$ & $1 \cdot 567(+0 \cdot 1 \%)$ \\
\hline$f_{3}$ & Lumped & $4 \cdot 301(+141 \cdot 0 \%)$ & $2 \cdot 257(+26 \cdot 8 \%)$ & $1 \cdot 562(-12 \cdot 2 \%)$ & $1.755(-1.4 \%)$ \\
\hline $1.780 \mathrm{~Hz}$ & Consistent & $2 \cdot 168(+21 \cdot 8 \%)$ & $1 \cdot 887(+6 \cdot 0 \%)$ & $1.793(+0.7 \%)$ & $1 \cdot 785(+0 \cdot 3 \%)$ \\
\hline
\end{tabular}

out that, for similar accuracy, the use of consistent mass matrices allows a significant reduction in the number of elements or degrees of freedom.

\section{EXAMPLE: DYNAMIC ANALYSIS OF MASONRY BRIDGE}

\subsection{Description of the structure}

The ability of the model to simulate the dynamic behaviour of complex structures is shown through its application to the modal vibration analysis of an actual masonry multispan arch bridge. This construction was previously subjected to a dynamic load test, so that experimental results are available and can be used in order to appraise the accuracy of the numerical predictions. This case was also selected because of the very good condition of the construction and the monolithic, almost solid-like elastic response shown.

The bridge of Periques was built during the 12th century near Barcelona, Spain. It has a total length of $51.6 \mathrm{~m}$ and consists of four masonry arches spanning 8.2, 15.6 (main arch), 12.1 and $6 \cdot 1 \mathrm{~m}$. (Figures 9 and 10). The arches are supported on three approximately square piers with sides of $34.25 \mathrm{~m}$. As is common in medieval construction, the platform is very narrow, being only $3.1 \mathrm{~m}$ wide.

The arch rings, consisting of one or two layers of sandstone voussoirs, have a depth of $0.4 \mathrm{~m}$ in the end arches, $0.70 \mathrm{~m}$ in the main one, and $0.5 \mathrm{~m}$ in the central one (Figure 10). The external walls of piers and spandrels are also made of sandstone ashlars. 


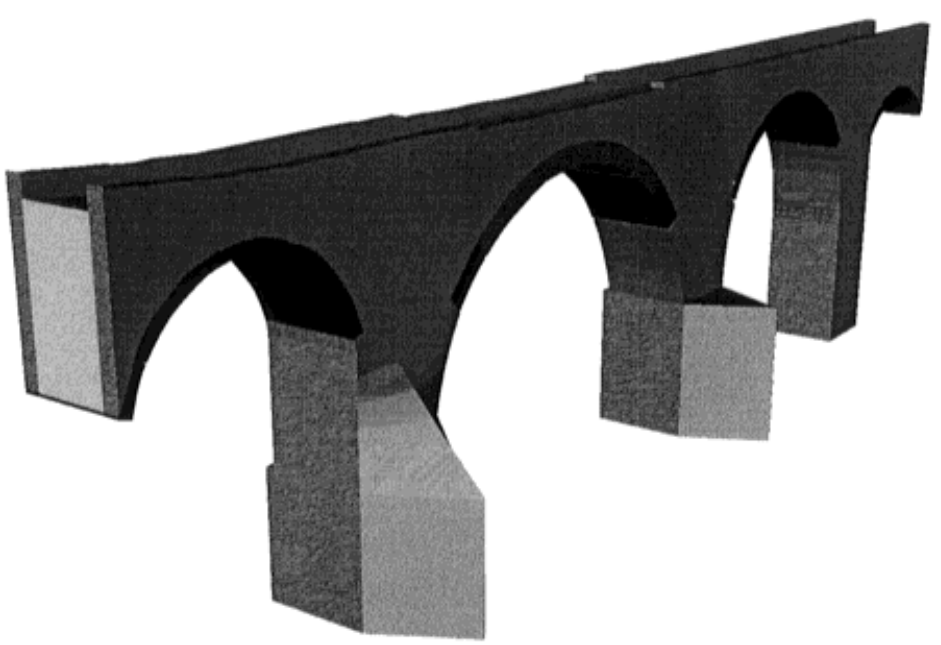

Figure 9. Perspective of the structural model of the Periques bridge
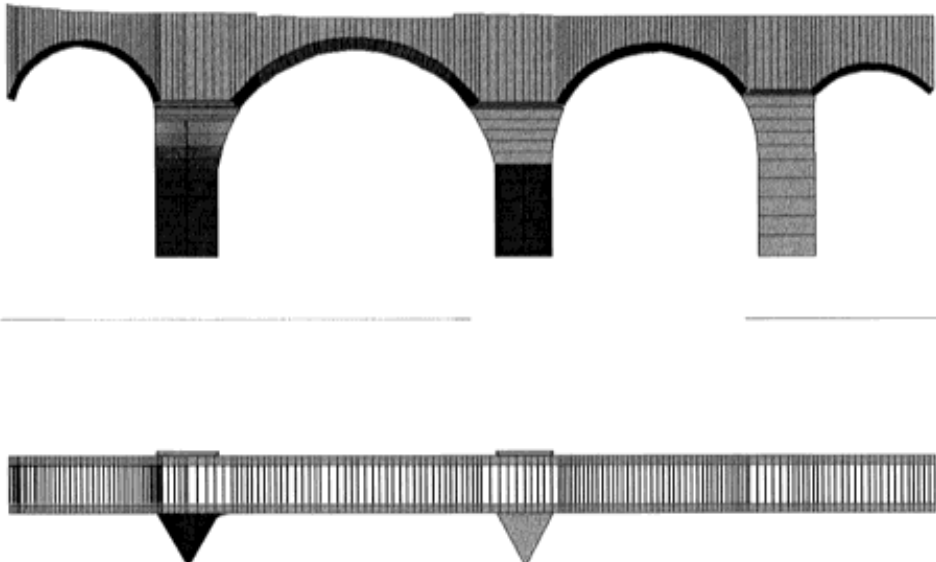

Figure 10. Plan and elevation of the model of the bridge

The entire structure shows a very good state of preservation, with only a small section of the main arch being replaced by brick fabric after damage caused during a Civil War in 1875 .

\subsection{Dynamic load test}

In order to carry out the dynamic test, the structure was excited by the impact provided by making the back axle of a truck, $120 \mathrm{kN}$ loaded, descend from a $15 \mathrm{~cm}$ step placed on the crown of the main arch. The same operation was repeated on the central arch. Nine accelerometers located at significant points recorded the vibrations of the structure in the three directions (vertical, longitudinal, and transverse to the axis of the bridge).

The spectral analysis performed based on the time-history signal allowed identification of the set of natural frequencies and modes of vibration indicated in Table III. In spite of the purely vertical excitation introduced, transverse and longitudinal motions were identified in addition to the vertical vibration. 
Table III. Experimental and analytical frequencies of vibration of the bridge

\begin{tabular}{ccccc}
\hline Mode & $\begin{array}{c}\text { Test } \\
\text { frequency } \\
(\mathrm{Hz})\end{array}$ & $\begin{array}{c}\text { Test } \\
\text { predominant } \\
\text { movement }\end{array}$ & $\begin{array}{c}\text { Analytical } \\
\text { frequency } \\
(\mathrm{Hz})\end{array}$ & $\begin{array}{c}\text { Analytical } \\
\text { predominant } \\
\text { movement }\end{array}$ \\
\hline 1 & $4 \cdot 9$ & Transverse & $5 \cdot 2$ & Transverse \\
2 & $6 \cdot 0$ & Transverse & $6 \cdot 6$ & Transverse \\
3 & $9 \cdot 1$ & Longitudinal/transverse & $8 \cdot 9$ & Longitudinal \\
3 bis & & $9 \cdot 1$ & Transverse & Vertical/transverse \\
4 & $11 \cdot 0$ & Vertical/transverse & $10 \cdot 9$ & Vertical \\
5 & $12 \cdot 7$ & Vertical & $12 \cdot 7$ & Vertical \\
6 & $13 \cdot 25$ & Vertical & $13 \cdot 0$ & \\
\hline
\end{tabular}

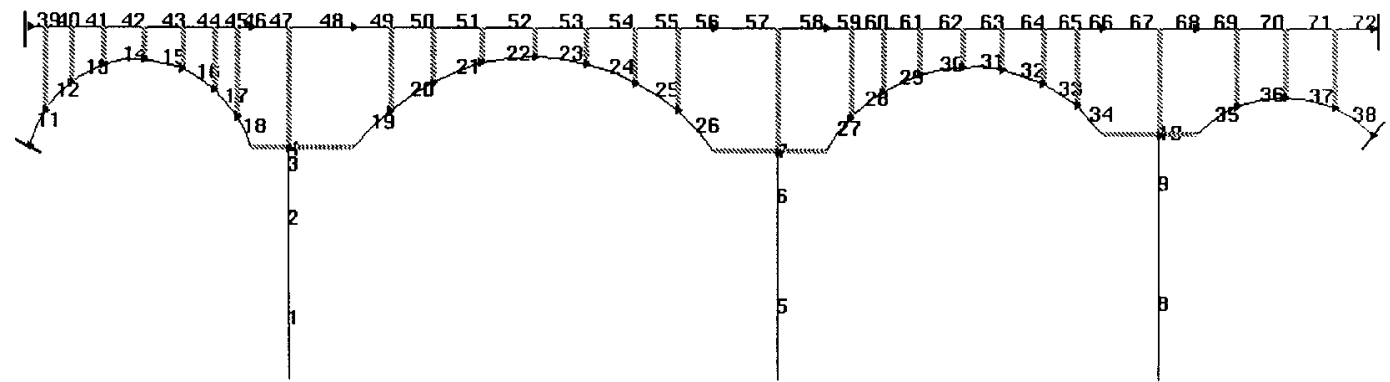

Figure 11. Model of Periques bridge including pier elements (1-10), arch elements (11-38), spandrel elements (39-72) and rigid links connecting them

\subsection{Numerical model}

The numerical simulation was carried out on the structural model shown in Figures 9-11. Each arch ring was discretized in eight-curved elements, while the piers were discretized with a set of three vertical, variable cross-section elements.

The modelling of such a structure by means of one-dimensional, albeit curved elements with variable cross-section, required the inclusion of specific devices in order to adequately take into account the resisting contribution of its main parts. First, rigid connections were introduced between the arch springs and piers so as to treat the intermediate portion above the pier as an undeformable body.

Second, the stiffening action of the spandrel walls was simulated by means of an equivalent system of horizontal, variable cross-section elements placed on the rings and linked to them by a set of springs (Figure 11). These springs were defined so that only the relative motion normal to the ring surface was restrained. ${ }^{21}$

The model included 72 linear elements in piers, arches and spandrels, together with the necessary 29 springs used to simulate the connection between them. The entire system included 444 degrees of freedom.

The mechanical properties of the materials were estimated from the previous experience of the authors in the study of similar ancient constructions. For ashlar masonry a deformation modulus of $8000 \mathrm{MPa}$, a shear modulus of $3000 \mathrm{MPa}$, and a density of $2400 \mathrm{~kg} / \mathrm{m}^{3}$ were considered; for brick masonry a deformation modulus of $4000 \mathrm{MPa}$, a shear modulus of $1500 \mathrm{MPa}$, and a density of $1800 \mathrm{~kg} / \mathrm{m}^{3}$ were considered; and for the infill a deformation modulus of $50 \mathrm{MPa}$, a shear modulus of $20 \mathrm{MPa}$, and a density of $2400 \mathrm{~kg} / \mathrm{m}^{3}$ were considered. 

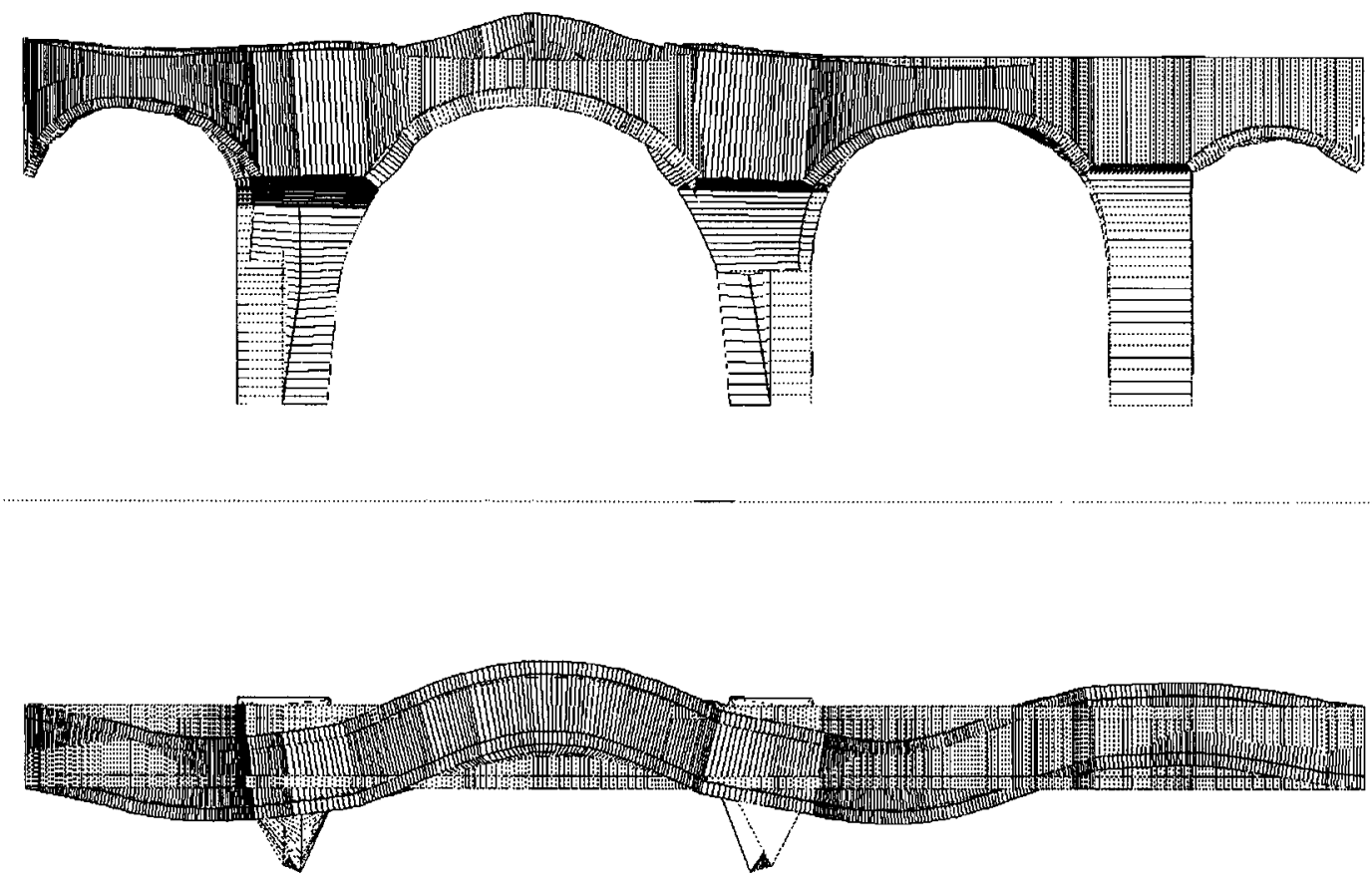

Figure 12. Plan and elevation of the fourth mode $(10.9 \mathrm{~Hz})$
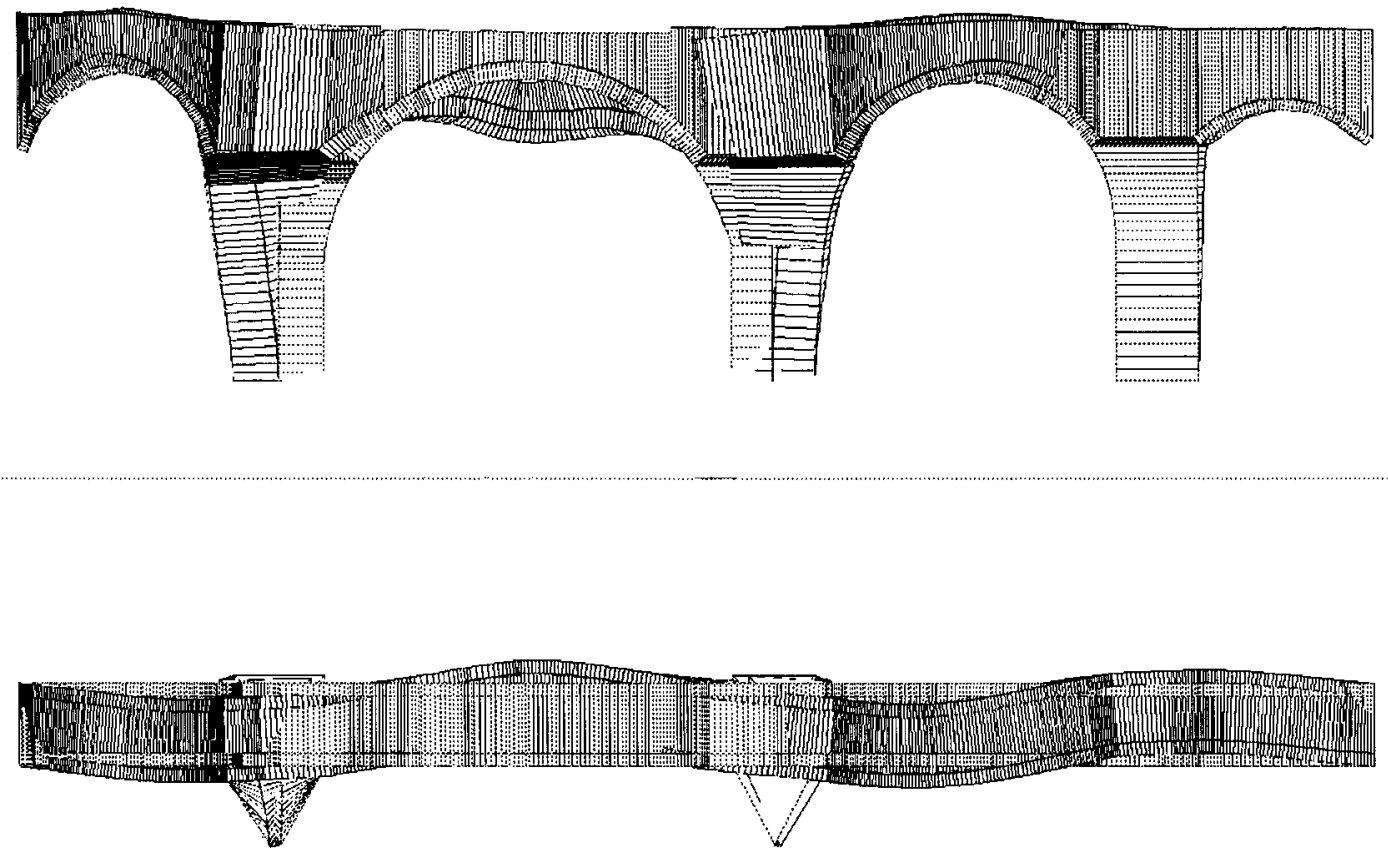

Figure 13. Plan and elevation of the fifth mode $(12.7 \mathrm{~Hz})$ 

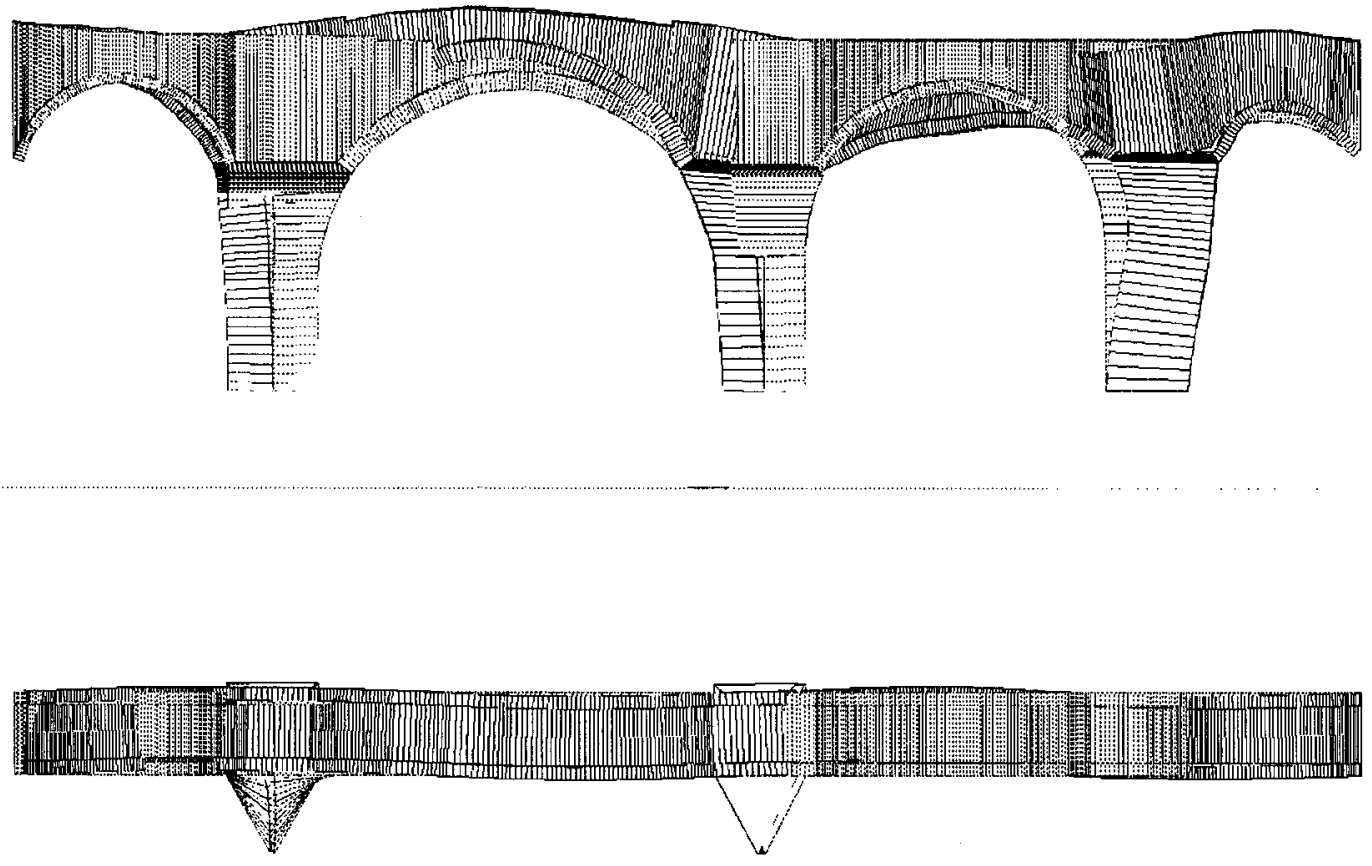

Figure 14. Plan and elevation of the sixth mode $(13.0 \mathrm{~Hz})$

\subsection{Results of modal analysis}

The results of the numerical simulation for the first eight frequencies and modes of vibration are shown in Table III. As can be observed, the general agreement between experimental and analytical results of frequency values is very satisfactory.

The modes of vibration numbered 3 (longitudinal) and $3^{\prime}$ (transverse), numerically predicted with frequencies very close to $9 \mathrm{~Hz}$, cannot be distinguished from each other according to the experimental results. However, an experimental frequency of $9 \cdot 1 \mathrm{~Hz}$ was detected which included longitudinal and transverse motion.

The more significant difference which exists between the experimental and numerical frequencies obtained on the 1st and 2nd transverse modes is justified by the strong dependence of these values on the geometry and internal composition of the cutwaters of the bridge, as shown by complementary simulations.

The best agreement is observed, as would be expected, for frequencies related to predominantly vertical modes (4th, 5th and 6th, Table 3). Although these three correspond to similar vertical waves, the 4th and 5th modes (Figures 12 and 13) include a significant transverse displacement. The tendency of this structure to mobilize a spatial response, even under a purely vertical excitation, shows the need to use a 3D spatial model in order to carefully characterize its dynamic behaviour.

\section{CONCLUSIONS}

A generalized matrix formulation was presented and extended to the linear dynamic analysis of spatial structures consisting of one-dimensional curved elements with arbitrary and variable cross-section. This formulation allows the accurate modelling of any structure formed by such elements with a reasonably small number of degrees of freedom. Since the proposed extension did not require additional hypotheses either on the kinematics of the structure or on the stress field, the accuracy of the results was conditioned only by the techniques adopted for the numerical integration. However, a description of the acceleration field was introduced in order to build a mass matrix referring to the nodal variables. The resulting mass 
matrix objectively takes into account the internal distribution of both stiffness and mass, with no additional assumptions needed.

The study of some examples showed that the proposed formulation approximates the dynamic behaviour of spatial framed structures more accurately than conventional methods. Also, for the same accuracy, the proposed method requires a smaller number of elements though it carries out more computations on each of them. Due to this, the calculation time is directly controlled by the number of sections to be integrated and, to a smaller degree, by the system of equations, since the required number of degrees of freedom is maintained at a minimum even in complex examples.

\section{ACKNOWLEDGMENTS}

This study was developed with the financial support of the Inter-Ministerial Commission of Science and Technology of the Spanish Government for the project 'Development and testing of techniques for the structural analysis of ancient buildings of the historical architectural heritage' (SEC93-1160).

The dynamic test of Periques bridge was commissioned and funded by Servei de Patrimoni Local of the Diputació de Barcelona.

\section{REFERENCES}

1. F. Baron, 'Matrix analysis of structures curved in space', J. Struct. Div., ASCE 87 (ST3), 17-38 (1961).

2. M. Mahasuverachai and G. H. Powell, 'Inelastic analysis of piping and tubular structures', EERC Report 82/27, Earthquake Engineering Research Center, University of California, Berkeley, 1982.

3. I. Carol and J. Murcia, 'Nonlinear time-dependent analysis of planar frames using an exact formulation-I. Theory', Comput. Struct. 33 (1), 79-87 (1989).

4. A. R. Marí, Modelos unidimensionales para el análisis no lineal en el tiempo de estructuras de hormigón armado y pretensado Department of Construction Engineering, Universitat Politènica de Catalunya, Barcelona, 1987.

5. G. E. Blandford and G. C. Glass, 'Static/Dynamic Analysis of Locally Buckled Frames', J. Struct. Engng. ASCE 113(2), 363-380 (1987).

6. C. A. Zeris and S. A. Mahin, 'Analysis of reinforced concrete beam-columns under uniaxial excitation', J. Struct. Engng. ASCE 114 (ST4), 804-820 (1988).

7. E. Spacone, F. C. Filippou and F. Taucer, 'A fiber beam-column model for non-linear analysis of R/C frames: Part I. Formulation', Earthquake Engng. Struct. Dyn. 25(7), 711-725 (1996).

8. E. Spacone, F. C. Filippou and F. Taucer, 'A fiber beam-column model for non-linear analysis of R/C frames: Part II. Applications', Earthquake Engng. Struct. Dyn. 25(7), 727-742 (1996).

9. O. C. Zienkiewicz and R. L. Taylor, The Finite Element Method, 4th edn, Vol. 2, McGraw-Hill Book Company, London, 1991.

10. J. W. Wekezer, 'Free vibration of thin-walled bars with open cross sections', J. Engng. Mech., ASCE 113(10), 1441-1453 (1987).

11. J. W. Wekezer, 'Vibrational analysis of thin-walled bars with open cross sections', J. Struct. Engng. ASCE 115(12), 2965-2978 (1989).

12. M. Eisenberger and Y. Reich, 'Static, vibration and stability analysis of non-uniform beams', Comput. Struct. 31(4), 567-573 (1989).

13. S. Oral, 'Anysoparametric interpolation in hybrid-stress Timoshenko beam element', J. Struct. Engng. ASCE 117(4), 1070-1078 (1991).

14. A. K. Gupta, 'Vibration of tapered beams', J. Struct. Engng. ASCE 111 (1), 19-36 (1985).

15. J. Courbon, Resistance des Matériaux, Tenth Edition, Vol. 2, Ed. Dunod, Paris, 1964.

16. C. Molins, P. Roca and A. R. Marí, 'Una formulación matricial generalizada. Parte I: análisis estático', Revista Internacional de Métodos Numéricos en Ingeniería 10 (4), 317-339 (1994).

17. J. S. Archer, 'Consistent matrix formulations for structural analysis using finite element techniques', $A I A A J .3,1910-1918$ (1965).

18. C. Molins, P. Roca and A. H. Barbat, 'Una formulación matricial generalizada. Parte II: análisis dinámico', Revista Internacional de Métodos Numéricos en Ingeniería 11 (1), 23-36 (1995).

19. S. Timoshenko, D. H. Young, and W. Weaver, Vibration Problems in Engineering, Wiley, New York, USA, 1974.

20. Y. F. Young and A. C. Scordelis, 'An analytical and experimental study of Helicoidal beams', J. Struct. Div. ASCE 84 (ST5), 1756:1-29 (1958)

21. C. Molins, 'Un model per a l'anàlisi del comportament resistent de construccions de maçoneria, Ph.D. Thesis, Universitat Politècnica de Catalunya, Barcelona, 1996 